\title{
Attending Emotionally to Fiction
}

\author{
Cain Todd
}

Published online: 19 February 2013

(C) Springer Science+Business Media Dordrecht 2013

\section{Introduction}

Philosophers have long been concerned with what is generally known as the paradox of fiction. This is the prima facie puzzling phenomenon that we appear to have emotional responses to fictional characters, events and situations that we know to be fictional, and yet our ordinary, everyday emotional responses in non-fictional contexts appear to possess as essential components various features that preclude their being directed at fiction. The two such features generally cited are (a) existential beliefs about the relevant objects and their properties and (b) connections to behaviour and action. Henceforth I will normally refer to the relevant responses as 'F-emotions,' where this is shorthand for 'fiction-directed emotions.'

The paradox has spawned a large literature and there are a number of more or less plausible explanations of it on the market. Nonetheless, to my mind no account has yet succeeded in providing a comprehensive resolution, primarily because the paradox raises some deep and complex issues about the nature of our engagement with fiction, the relationship between imagination, belief and emotion, and different modes of attention, that have yet to be adequately recognised by philosophers working on this topic, let alone discussed. This paper aims to make some progress in exploring these issues by addressing and offering a solution to one central problem for which no other account of the paradox has yet provided an adequate solution. I shall refer to it as the 'Knowledge Problem':

\footnotetext{
C. Todd $(\bowtie)$

Department of Politics, Philosophy and Religion, Lancaster University, Lancaster LA1 4YL, UK

e-mail: c.todd@lancaster.ac.uk

C. Todd

University of Fribourg, Fribourg, Switzerland
} 
Knowledge Problem (KP): How can we have F-emotions when we know that - in the sense that we are occurrently aware that, or are attending to the fact that - the objects of our responses are fictional?

That we are (in the normal, rational case) in some sense aware of the fictionality of the objects to which we respond emotionally is evident from the fact that our behavioural responses to fictional scenarios are strikingly different from those caused by non-fictional scenarios; we do not leap onto the stage to save the heroine, though we may shed real tears at her plight. It is also evident from the apparent fact that our affective reactions to fiction feel similar but not identical to our reactions to non-fiction; we are sad at the fate of Anna Karenina, yet perhaps rather less sad (or perhaps sad in a different way) than we would be had we known a real such Anna personally. Any solution to the Knowledge Problem must explain these two features of our emotional responses to fiction. ${ }^{1}$

I will argue that we should understand the role played by the imagination in our engagement with fiction as functionally equivalent to that which it plays under the guise of 'acceptance' in practical reasoning, suggesting that the same underlying cognitiveaffective mechanisms are involved in both activities. The first part of this paper will thus be concerned with demonstrating the similarities between practical reasoning and our engagement with fiction. Our imaginative engagement with fiction, I claim, un-problematically arouses emotions, but only to the extent that we are not occurrently attending to our epistemic relation to the fiction i.e. fully attending to the fact that the object of our response is merely fictional. Our ability to bracket fictionality, central to our ability to engage in imaginative practical reasoning projects, is thus a fundamental part of our cognitive architecture and not, as such, puzzling. In order to further illuminate this notion of bracketing, the second part of the paper examines one central feature of the phenomenology of emotion and attention, namely, their partial non-attributiveness, a feature which is crucial to understanding our emotional engagement with fiction.

\section{From Imagination to Emotion}

The most popular solutions to the paradox consist in loosening emotional responses from their purported tightly-knit connections to belief and action and positing that real emotions can be caused by mere unasserted thoughts, such as those characteristic of the imagination or make-believe, and directed at the contents of such thoughts. ${ }^{2}$ In addition to the intuitive plausibility of such claims, there is

\footnotetext{
${ }^{1}$ See Timothy Schroeder and Carl Matheson, "Imagination and Emotion," in S. Nichols (ed.), The Architecture of Imagination: New Essays on Pretence, Possibility, and Fiction (Oxford: Clarendon Press, 2006), p. 19-40.

2 For example: Alex Neill, "Fiction and the Emotions," American Philosophical Quarterly 30 (1993): 1-13; Peter Lamarque, Fictional Points of View (New York: Cornell University Press, 1996); Gregory Currie, "The Moral Psychology of Fiction," Australasian Journal of Philosophy 73 (1995): 250-259; Currie, "The Paradox of Caring: Fiction and the Philosophy of Mind," in M. Hjort and S. Laver (eds.), Emotion and the Arts (Oxford: OUP, 1997), p. 63-77; Berys Gaut, "Reasons, Emotions and Fiction," in M. Kieran and D. Lopes (eds.), Imagination, Philosophy and the Arts (London: Routledge, 2003), p. 15-34; Stuart Brock, "Fictions, Feelings, and Emotions," Philosophical Studies 132 (2007): 211-242.
} 
increasing empirical evidence showing that certain genuine emotional responses, and some of their associated action tendencies, can be aroused equally by imaginary and real life objects and situations. ${ }^{3}$ Furthermore, drawing also on psychological and neuroscientific research, recent prominent philosophical theories of emotion argue for the same conclusion. ${ }^{4}$

So, for example, based on the examination of a number of empirical studies, Tamar Gendler contends that our capacity to respond with genuine emotions to merely imaginary stimuli is a fundamental part of our cognitive architecture. ${ }^{5}$ Specifically, she emphasises Antonio Damasio's research, which appears to demonstrate that practical reasoning tasks involving imagined scenarios concerning our own future decisions and actions are successful only insofar as they essentially involve somatically encoded emotional responses. ${ }^{6}$

The connection between imagination and practical reasoning is one that I shall pursue below, but all these accounts fail to confront the puzzle of explaining just how one can have an emotional response of, say, fear, towards something that is known, occurrently with the emotional state, to be a mere thought or merely imaginary, or towards a kind of imagining. That is, even if we allow that the imagination can ground genuine emotional responses, we quickly run up against the Knowledge Problem (KP).

In a recent paper, Schroeder and Matheson do directly address KP, claiming that very early in childhood "our brains have somehow begun to learn how to assess these conflicting pieces of information," and they suggest that "because one is generally conscious that these events are fictional - i.e. one represents them as fictional $-\ldots$ this makes all the difference to one's emotional life. If, somehow, one ceases occurrently to represent the fictional nature of one's source, one will naturally be expected to feel more as one would feel were the source factual."7

These responses are promising in suggesting, like Gendler, that our ability to engage with fiction emotionally is a fundamental part of our cognitive architecture, but they do little more to show in what ways it is fundamental. Their discussion hints at the important idea, and the point of departure for my account, that a

\footnotetext{
3 Timothy Schroeder and Carl Matheson, "Imagination and Emotion," in S. Nichols (ed.), The Architecture of Imagination: New Essays on Pretence, Possibility, and Fiction (Oxford: Clarendon Press, 2006), pp. 19-40; Antonio Damasio, Descartes' Error (London: Vintage Books, 1994); Tamar Gendler and Karson Kovakovich, "Genuine Rational Fictional Emotions", in M. Kieran (ed.), Contemporary Debates in Aesthetics and the Philosophy of Art (Oxford: Blackwell, 2006), pp. 241-253.

4 Jinhee Choi, "Fits and Startles: Cognitivism Revisited," The Journal of Aesthetics and Art Criticism 61 (2003): 149-157; Jesse Prinz, Gut Reactions: A Perceptual Theory of Emotion (New York: Oxford University Press, 2004); Jenefer Robinson, Deeper Than Reason: Emotion and its Role in Literature, Music, and Art (Oxford: Clarendon Press, 2005).

5 Tamar Gendler, "Imaginative resistance revisited," in S. Nichols (ed.), The Architecture of Imagination: New Essays on Pretence, Possibility, and Fiction (Oxford: Clarendon Press, 2006), pp. 149-174; see also Tamar Gendler and Karson Kovakovich, "Genuine Rational Fictional Emotions," in M. Kieran (ed.), Contemporary Debates in Aesthetics and the Philosophy of Art (Oxford: Blackwell, 2006), pp. 241-253.

${ }^{6}$ Gendler (2003), op. cit., p. 136

7 Schroeder and Matheson (2006), op. cit., pp. 34-35.
} 
resolution of the paradox may hinge on the nature and role of our occurrent representation of, or attention to, the fictionality of the objects to which we respond.

An interesting solution that appeals to a similar idea has been proposed by David Suits, who argues that when we are appropriately engaged with a fiction we actually believe in the fiction and are hence caught up in the story to the extent that we are not occurrently, fully aware of its fictionality as such. We do not somehow lose touch with reality, but rather the physical situation one is in is peripheralized. ${ }^{8}$ In short, Suits' resolution of the paradox consists in claiming that one does believe in the fiction, where belief consists in some degree of commitment to the fiction sufficient to ground appropriate and genuine emotional responses. This belief in the fiction - qua degree of commitment - is thus compatible with not believing in the reality of the fiction, where this involves not being occurrently fully aware of/committed to its fictionality as such.

There is much that is plausible and compelling about Suits' analysis and it offers a promising explanation of the paradox, insofar as the usual cases of F-emotions involve us holding, to different degrees, attitudes of commitment to apparently incompatible states of affairs; so long as we are not occurrently, fully focussed to the same degree on them, and hence on their incompatibility. Indeed this is the claim that I will, in a qualified form, be concerned to defend. However, Suits' account involves unwarrantedly conflating belief and imagination (as states of commitment lying on the same continuum), but it is simply not plausible to maintain that the kind of commitment one gives to fictional propositions is a state of belief; rather, it involves a particular kind of imaginative engagement. ${ }^{9}$

In order to explain the intensity with which we can lose ourselves in fictional worlds in the way that is required to ground our affective responses to them, to properly appreciate works of fiction, and to account for their value, we must accept that when we engage emotionally with fiction, and when the fiction warrants it, we commit strongly to the propositions expressed therein. That is, we imaginatively commit ourselves to accepting the fictional truths they provide, where this involves committing ourselves to a certain amount of authorial authority and to assenting to the propositions expressed. Naturally, this commitment is subject to a number of complex conditions involving a recognition of authorial intention, genre and other conventional constraints, as well as a sensitivity to features such as the coherence and plausibility of the narrative, the reliability of the narrator, and any number of further complex factors involved in understanding and interpretation. ${ }^{10}$

In order to see just what this kind of imaginative commitment is and how it grounds our emotional responses in a way required to address KP we can, I suggest, turn to the notion of acceptance that some philosophers have posited to play a central role in practical reasoning. I will argue, first, that this type of acceptance is or at least centrally involves an act of imagining, and second that we should

\footnotetext{
${ }^{8}$ Suits (2006): op. cit., pp. 380-381.

9 For further discussion of these issues see See Schroeder and Matheson (2006), op. cit., p. 25; Currie, "Desire in Imagination," in T. Gender and J. Hawthorne (eds.), Conceivability and Possibility (Oxford: Clarendon Press, 2002), pp. 201-221: 209; Gendler and Kovakovich (2005), op. cit.

${ }^{10}$ Kendall Walton, Mimesis as Make-believe (London: Harvard University Press, 1990); Gendler (2006), op. cit.; Lamarque (2002), op. cit.
} 
understand the role played by the imagination in our engagement with fiction as functionally equivalent to that which it plays in practical reasoning. As such, I suggest that the same underlying cognitive-affective mechanisms are involved in both activities and that there are good evolutionary reasons for the existence of such mechanisms.

\section{Acceptance and Imagination in Practical Reasoning}

According to Jonathan Cohen and Michael Bratman, certain practical pressures can lead to the acceptance of propositions for the purposes of deliberation, where these propositions need not be believed and may even be disbelieved. ${ }^{11}$ So, to take a prosaic example, I may accept for prudential reasons that it will rain this evening in the sense that I take this for granted in my deliberation and bring along an umbrella, even if I would not be willing to bet on it and have good evidence for forming a belief to the contrary. Acceptance, that is, plays a central role in practical reasoning, and differs from belief in a number of important ways. Cohen, for instance, argues that whereas beliefs are passive dispositions to feel it true that $p$, accepting is a context relative, voluntary mental act. ${ }^{12}$ Bratman too contrasts acceptance with belief in holding that the former, unlike the latter, is context-independent, voluntary, does not essentially aim at truth, and is not subject to an ideal of integration governed by constraints of consistency and coherence with regard to the rest of one's beliefs: "I will not reasonably and at one and the same time believe that $p$ relative to one context but not relative to another. In contrast, I might reasonably accept that $p$ relative to one context but not relative to another... One may believe (have a high degree of confidence in) a proposition and still reasonably not accept it in certain contexts. And even in the absence of belief (high degree of confidence) that $p$ I can sometimes reasonably accept that $\mathrm{p}$ in an appropriate practical context." 13 Can we identify acceptance with an act of imagining? Both Bratman and Cohen appear explicitly to reject any attempt to do so, insisting that acceptance is not to be identified with pretence or supposition, for unlike these latter states, acceptance is not merely temporary but "implies commitment to a policy of premising that $\mathrm{p}$ " and is normally justified by reasons. ${ }^{14}$ Further, acceptance "is tied more directly to action than is mere supposition; and it is tied more directly to practical reasoning than is mere pretence." 15

Nonetheless, there are good reasons for thinking of acceptance as an imaginative act. We can admit that acceptance is different from mere supposition, and from pretence, in the way that Bratman and Cohen narrowly characterise them, but it

\footnotetext{
11 Jonathan Cohen, "Belief and Acceptance," Mind 98 (1989): 367-389; Michael Bratman, "Practical Reasoning and Acceptance in a Context," Mind 101 (1992): 1-15.

12 Cohen (1989), op. cit., p. 368.

13 Bratman (1992), op. cit., p. 9.

14 Cohen (1989), op. cit., p. 368; Jonathan Cohen, An Essay on Belief and Acceptance (Oxford: Clarendon Press, 1992), pp. 13-14.

15 Bratman (1992), op. cit., p. 9. Cf. Cohen (1992), op. cit., pp. 12-13.
} 
seems clear that insofar as practical reasoning involves envisaging hypothetical and future scenarios, these are things that are imagined, and imagining that $p$ is generally held to be a voluntary act, to be subject to some degree to the will, and what we imagine may differ between contexts. Moreover, when we engage in these imaginative projects, and those characteristic of our engagement with fiction, we are able (and in the case of fiction must if we are to engage appropriately), as many philosophers have noted, to preserve the same inference patterns as those governing the equivalent belief states. ${ }^{16}$ Most importantly, however, it is clear that certain types of imaginative activity are far more 'full-blooded' than mere supposition and possess close connections to emotion, action, and practical reasoning.

As already mentioned, there is good reason to think that genuine emotional responses, and some of their associated action tendencies, can be aroused by the imaginary as well as by real life objects and situations. Although Bratman and Cohen offer little discussion of the involvement of emotions and affective states in practical reasoning, it is plausible, in light of Damasio's research, to think that acceptance in the context of practical reasoning will often give rise to and draw upon such states. For such reasoning will often require us to realise concretely the potential consequences of our actions for our own welfare, and the arousal of autonomic, somatic responses associated with (or constituting) emotional states is the most effective way of doing this. Moreover, such reasoning will depend in part on determining how we might feel about certain decisions or even perhaps what the best thing to feel should be. Practical reasoning, that is, can often be directed at our own emotional responses, insofar as we take these to be rational and educable. Hence, as many have pointed out, the ability to simulate ourselves and others in various imaginary situations can play an important role not just in theoretically deliberating about what to do, but in how we would feel were we to do it. ${ }^{17}$

In light of these considerations it is, I think, not unreasonable to hold that acceptance in practical reasoning is, or at least centrally involves, an act of imagining. A case for the stronger reading - identifying acceptance with imagining - is made by David Velleman, who argues that accepting a proposition is a way of regarding that proposition as true, and that where imagining that $p$ involves engaging in a mental fiction it involves imagining that $p$ is true. Imagining is therefore a way of accepting a proposition. In contrast to Cohen and Bratman, however, Velleman holds that belief is also a state of acceptance for it too is a way of regarding a proposition as true. The main difference between belief and imagination, Velleman contends, is that only the former involves regarding a proposition as true "with the aim of so regarding it only if it really is. Thus to believe a proposition is to accept it with the aim of thereby accepting its truth."18

Crucially, this difference is not sufficient to make a difference between the motivational roles of belief and imagination, for even the latter can motivate us to

\footnotetext{
16 See for example Currie and Ravenscroft (2002), op. cit.; Meskin and Weinberg (2003), op. cit.

17 Currie (1995), op. cit; Kendall Walton "Spelunking, Simulation, and Slime: On Being Moved by Fiction," in M. Hjort and S. Laver (eds.) Emotion and the Arts (New York: Oxford University Press, 1997), pp. 37-49; Currie and Ravenscroft (2002), op. cit.

18 David Velleman, The Possibility of Practical Reason (Oxford: Clarendon Press, 2000), pp. 250-251.
} 
act on the conclusions reached in light of these imaginative projects: we may be led to cook kippers and custard for our friends, having put together in imagination our olfactory memories of each; we may be led to commit that long-envisaged murder, having imagined a way to carry it out undetected and in the process come to realize that we might not feel overly guilty as a consequence.

Focusing on children's games of pretence and relying heavily on Kendall Walton's well-known discussion of these, Velleman holds that the actions performed in such games cannot be explained in terms of acting from beliefs and desires, but must be explained as acting directly out of what is imagined. Otherwise, belief-desire explanations of pretence attribute to children a precocious grip on reality even during pretend play, in which their actions are to be described as deliberately producing false appearances. ${ }^{19}$

For example, on such accounts the child pretending to be an elephant performs actions believed to be elephant-like, aimed at realising the desire to behave like an elephant. But as Velleman rightly notes, this misrepresents the nature of such play and entails attributing to young children an implausibly strong grip on (or occurrent attention to) the distinction between fiction and reality: "In order to enter into the fiction, the child would have to act it out; and in order to act it out...he would have to act out of imagining it, not out of a desire to represent it in action. A child who was motivated by such a desire would remain securely outside the fiction, thinking about it as such - that is, as a fiction to be enacted." ${ }^{20}$ Although Velleman's discussion centres on the role of motivation and action in imagination and pretend play, I think the very same points carry across to our emotional engagement with fiction, which if not actually involving actions on our part, does involve, as Walton outlined, playing a kind of game of make-believe which arouses as a direct consequence of imaginative engagement certain physiological responses and action tendencies. $^{21}$ So, for example, as Paul Harris observes, holding that F-emotions result from merely pretending that $p$ is real would also entail, implausibly, saddling very young children with the ability to form a cognitively complex attitude. We must, instead, understand these responses as arising directly from imaginative engagement with the fiction. ${ }^{22}$

Whatever one thinks about Velleman's identification of belief as a state of acceptance, his account is on the right track in showing how to understand both imagining and believing as states of commitment to propositions, differing in their relation to the truth of these, but similar in their affective and motivational outputs. As such, the acceptance involved in practical reasoning is, I contend, best thought of as a state of imaginative commitment. I want to show now that the role the imagination plays in fictional engagement is - modulo certain considerations - the very same role that imaginative acceptance plays in practical reasoning. Seeing how

\footnotetext{
19 Walton (1990), op. cit.; Compare Paul Harris, The Work of the Imagination (Oxford: Blackwell, 2000); Cohen (1992), op. cit., p. 22

20 Velleman (2000), op. cit., p. 259.

21 Walton (1990), op. cit.

22 Harris (2000), op. cit., p. 82.
} 
this is so illuminates the nature of our imaginative engagement with fiction and in particular the nature of our affective responses to it.

\section{Imaginatively Accepting Fiction}

Prima facie, it might seem odd to draw a structural and functional similarity between our imaginative engagement with fiction and the role that acceptance plays in practical reasoning, let alone to posit that the underlying mechanisms are the same, even if we are persuaded that acceptance either is or centrally involves an act of imagining. After all, the point of acceptance is to deliberate about action, to come to a decision about the right thing to do from amongst a range of competing options. This explains why acceptance involves, in the words of Cohen, commitment to premising $p$, and also why such reasoning should intimately involve the arousal of affective states that have a direct bearing on planning, motivation and action. It is in our practical interest to be fully engaged in such deliberation. But this looks like an altogether different and more serious activity than playing games of make-believe, for fictional engagement is not normally concerned with what we ought to do in some possible 'real-world' scenario. Rather, the aim of this activity is, simply, enjoyment. Moreover, such deliberation essentially concerns the self, and if anything our engagement with fiction involves an escape from, or even loss of the self whilst following the adventures of fictional others.

In fact, of course, such a simplistic conception of the value of fiction can easily be challenged. We do often take ourselves to learn from fiction, to attribute to good fiction a serious cognitive value, and many philosophers have argued that fictional narratives in particular can give us moral knowledge, can educate our emotions, and can even affect our general values and world views. ${ }^{23}$ Fictions, that is, can be thought of as kinds of thought-experiments in ways that mirror the thought experiments of practical reasoning, and perhaps in certain cases they may even lead to action. We may, for example, be more likely to vote against government surveillance measures after reading 1984; to take vegetarianism seriously, or give money to animal protection charities after reading Disgrace; or turn to crime after seeing the ease with which casinos can be robbed in Ocean's Eleven. ${ }^{24}$

Moreover, a plausible evolutionary-psychological story can be told about the nature and value of appreciating fiction in engaging the imagination and emotions in just this way. As Paul Harris argues, for instance: "Had we not evolved a decisionmaking system in which the contemplation of possible lives and possible futures engaged our emotions at a somatic level, we would be less prone to spend as many hours as we do absorbed in fictional worlds." 25 That is, not only does our appreciation of fiction depend upon the exercise of cognitive resources that play a

\footnotetext{
23 Martha Nussbaum, Love's Knowledge: Essays on Philosophy and Literature (Oxford: Oxford University Press, 1992); Matthew Kieran, "Art, Imagination, and the Cultivation of Morals," Journal of Aesthetics and Art Criticism 54 (1996): 337-351.

24 See Gendler (2003), op. cit., for further discussion of cases that she labels 'affective transmission.'

25 Harris (2000), op. cit., p. 88.
} 
fundamental role in human behaviour and well-being, the engagement with fiction offers the perfect way of exercising and developing and these capacities.

Recall, further, that acceptance is voluntary and context-relative. I choose to accept $p$ for the purpose of some piece of practical reasoning that leads to action, but only in this specific context. In another context I might well choose not to accept $p$. Having chosen to accept $p$, however, we commit ourselves to $p$ in the sense that we let it guide our reasoning. Analogously, I contend, we choose to engage with a fiction, to allow the author to stipulate and construct the fictional truths of the narrative, in the hope of being (at least) entertained and emotionally moved. Having made this choice, however, we can and do get caught up in the fiction in ways that do not always appear to be conscious or voluntary. That is, we are committed to the propositions expressed in the work, letting them guide our emotional responses. Yet our state of engagement with fiction remains one of imaginative 'acceptance' rather than belief - insofar we are always capable of putting the book aside or just reminding ourselves that it is 'only fiction.' Moreover, what we accept in the context of one fiction we may refuse to accept in the context of another. Fictional works, that is, differ from each other in much the same way as practical reasoning contexts differ from each other in manifesting different practical projects.

If we think of imaginatively accepting $p$ in the case of fiction as involving committing ourselves to the propositions in that fiction, our acceptance can stem from an initial aim of mere aesthetic enjoyment and yet in the context of engagement be subject to the same sorts of constraints governing our commitment to $p$ in the case of practical reasoning. This is thus perfectly compatible with acceptance being the choice of which propositions to take as premises, for in this case the initial choice/acceptance simply governs all of the propositions in the fiction (modulo worries about imaginative resistance, unreliable narrators, and so on). Furthermore, the imagination in fictional contexts, far from being unconstrained, is governed by those complex rules and principles that determine what is fictionally true in the world of the fiction - e.g. the say-so of the author, a reality principle, principles of internal coherence and consistency, and so on. ${ }^{26}$ What is fictional is what is to be imagined and it is in this sense that "imagination aims at the fictional as belief aims at the true". ${ }^{27}$

Here there is an important analogue of Bratman's idea that "an agent's beliefs provide the default cognitive background for further deliberation and planning [where] practical reasoning admits of adjustments to this default cognitive background, adjustments in what one takes for granted in the specific practical context." ${ }^{28}$ Similarly in fiction, our engagement, and the fictional truths to which we commit, depends on - whilst also sometimes warping and questioning - certain background beliefs and assumptions. The author cannot in general explicitly stipulate absolutely everything that is true in a fictional world; instead, they need to draw on our present store of background beliefs about the real world, and arguably

\footnotetext{
${ }^{26}$ For example David Lewis, "Truth in Fiction," American Philosophical Quarterly 15 (1978): 37-46; Walton (1990), op. cit; see also Lamarque (2002), op. cit.

27 Walton (1990) ibid., p. 41.

28 Bratman (1992), op. cit., p. 10.
} 
also on our present stock of desires and values in order to move us and engage us in the ways required to appreciate the fiction. Plausibly, fiction emotionally involves us only insofar as it draws on relevant aspects of familiar reality. ${ }^{29}$

Thus, I have tried in this section to show that our imaginative engagement with fiction functions in the same way as it does when used as acceptance in practical reasoning. In both cases we imaginatively commit to the propositions and states of affairs belonging to some particular imaginative project, and in doing so we utilise the same cognitive-affective resources. In both cases such imaginative engagement/ commitment is (a) voluntary; (b) context-relative; (c) constrained in the relevant ways by the aim of engagement; (d) arouses emotions as a necessary part of understanding and engaging with the imaginative project, be it a fictional world or a practical reasoning task.

There are, however, inevitably differences. In particular, the motivation for our imaginative engagement is generally different in each case, for practical reasoning has instrumental value in leading us to action, whilst we turn to fiction primarily for enjoyment. As such, the self is necessarily implicated in the former, but not the latter. Yet these differences do not, I think, undermine the picture I am trying to paint, for we can and do have similar instrumental motivations for engaging with some fictions, and we may also enjoy the kinds of imaginative projects we undertake under the rubric of practical reasoning. The role of the imagination is, I contend, functionally the same in each case.

We are now in a position to see how this account of the nature of our imaginative engagement with fiction can be used to address the Knowledge Problem.

\section{Attending to Fiction and Bracketing Beliefs}

Fiction may also obviously conflict with what we believe, in just the way that what we accept for the purposes of deliberation may conflict with what is believed. In the latter case, Bratman holds that we have two options: "One may adjust the default cognitive background in two main ways: one may posit that $\mathrm{p}$ and take it for granted in one's practical context even though $\mathrm{p}$ is not believed (or given a probability of 1) in the default background; or one may bracket $\mathrm{p}$ in one's practical context even though $\mathrm{p}$ is believed in the default background. Positing and bracketing are two ways in which there can arise important differences, at the margins, between one's default cognitive background and one's context-relative adjusted cognitive background." 30 The relevant notion for us here is that of bracketing. In order to explain both how we are never unaware of fictionality - we never leap on stage - and yet can lose ourselves in imaginative engagement in the way required to ground F-emotions (i.e. to resolve the Knowledge Problem), I contend that the belief that we need to bracket in order to fully imaginatively engage with the work is the belief in the mere fictionality of the work. Unfortunately, Bratman himself does little to

\footnotetext{
${ }^{29}$ Currie (2002), op. cit.; Kreitman (2006), op. cit.

30 Bratman (1992), op. cit., pp. 10-11.
} 
articulate the notion of bracketing belief, but we can, I suggest, begin to make sense of it in terms of the notion of attention.

It should come as no surprise that our emotional engagement with fiction is normally hindered, weakened, or even on occasion thwarted by full and occurrent active attention to its fictionality. But what does it mean to be fully occurrently attending to the fictionality of the object of one's emotion? Psychologically, things are complicated. Clearly the activity of bracketing, like attending, admits of degrees, and can be more or less successful. We can deliberately focus on one feature at the expense of another; we can perhaps attend to two things simultaneously; we can switch and oscillate between objects of attention; we can also have our attention drawn, accidentally or deliberately, to features we had not noticed.

We do not generally oscillate between, as it were, losing ourselves in a story and reminding ourselves that it is only a story, or if we do we regard this as a suboptimal state of engagement, perhaps due to flaws in the narrative, or because for some other reason we are deliberately trying not to be emotionally moved by it. Why, otherwise, would we undertake so energetically all of those precautions designed to help peripheralize the external world - the fictionality of the fiction when trying to engage with fiction? We thus bracket (or try our best to bracket) the non-story context, the mere fictionality of a work when imaginatively accepting it; that is, when committing ourselves imaginatively to the propositions expressed therein. And here of course we are often aided, at least in the case of visual fictions, by those various conventions of appreciation such as dimmed lights, silence, enhanced acoustics, and so on.

In light of these brief remarks I think we can usefully, albeit for the moment roughly, distinguish here between a rather passive and dispositional notion of just being aware of, and a more active and occurrent conscious state which we could call attending to, focussing on, or representing as [fictional]. In the case of the former passive conception, I contend, we are never unaware of the fictionality of the object, in the sense that our state is one of voluntary acceptance, for we can always remind ourselves that it is only fiction and we do not leap onto the stage to save the imperilled heroine. But our belief in fictionality is appropriately bracketed, backgrounded, peripheralized, quarantined, when imaginatively and emotionally engaged with a fiction in the sense that we are not actively paying full attention to the fact that it is only fiction.

This notion of bracketing our belief in fictionality can be elucidated in two ways. First, consider this plausible account of the nature of propositional imagining offered by Brian O'Shaughnessy: "In imagining that $\mathrm{p}$, one has as the focus of one's mental attention only the state of affairs picked out by 'p'. It follows that, among other things, mental attention to one's epistemic relation to 'p' is excluded for the duration of the imagining. Hence in occurrently imagining that $\mathrm{p}$, one is not occurrently thinking of the fact that one only imagines that $\mathrm{p}$, or does not believe that $\mathrm{p}$, or that ' $\mathrm{p}$ ' is not true." 31 This well explains why it would indeed be puzzling

\footnotetext{
31 Brian O'Shaughnessy, Consciousness and the World (Oxford: Clarendon Press, 2000), p. 362; see also Kathleen Stock, "Thoughts on the 'Paradox' of Fiction," Postgraduate Journal of Aesthetics 3 (2006): 37-58. See also Schroeder and Matheson (2006), op. cit., p. 24.
} 
or impossible for F-emotions to occur where we were occurrently and fully attending to the work as fiction whilst at the same time being caught up in the story. For to be attending to the fact of fictionality just is to be attending to one's epistemic relation to $p$. It is the belief in this fact that we bracket when imaginatively engaging in fiction in the way, and degree, required to arouse F-emotions. Thus when we bracket, we cannot, in the usual case be paying full attention to the fictionality as such of the work with which we are imaginatively and emotionally engaged.

Note, however, that O'Shaughnessy's condition on imagining that $p$ is not as straightforward as he presents it here, for the ability to engage imaginatively with fiction by imagining that $p$ is subject to degree and hence can be more or less successful. It is thus dependent in part both on individual psychology, on certain conventions governing our engagement with fiction, and on particular works of fiction. As such, any plausible account of F-emotions must therefore allow for the contingency of our psychological states, but it must also account for the tension between competing attitudes - belief and imagination - which is also subject to degree and is not an unusual occurrence in our everyday engagement with works of fiction. Such tension, on my account, is a natural consequence of the fact that both imagination and belief are states of commitment that can motivate, and that our engagement with fiction depends on the extent that we succeed in bracketing the countervailing beliefs concerning the facts that one is imagining to be otherwise.

Granted these contingencies, the more one is focussing on the fictionality as such the less able one will be to emotionally engage, up to the limit of paying full simultaneous attention to incompatible states of affairs; hence the point of emphasising the condition of full and occurrent attention. The solution to the Knowledge Problem is thus relatively straightforward:

Solution to KP: In the normal cases one does not know that the object of one's engagement is merely fictional in the sense that one is not fully, occurrently, actively attending to the fictionality as such of the object towards which one's emotions are directed (and hence one's epistemic relation to this object). This is consistent with our being passively aware of p-as-fiction, however, since all that this requires is not actively attending fully to this fact whilst involved in the relevant propositional imagining. Attention comes in degrees and our ability to bracket is a fundamental part of our cognitive architecture, required for practical reasoning and for its role in appreciating fiction, and thus beneficial from an evolutionary perspective in respect of both. As such, this ability, and its application to fictional contexts, is not at all puzzling.

It is important to point out here, however, that I do not wish to exclude the possibility of unusual cases, cases where one can effectively pay full attention, simultaneously, both to the fictionality as such of $\mathrm{p}$ and yet also to the content in virtue of which one experiences F-emotions. In part, the possibility of such cases is largely a matter of understanding the nature of attention. It is thus important now to turn to the second way of elucidating the notion of bracketing, which is to examine more closely the phenomenology of attention and emotion. 


\section{Attention, Emotion, and Non-attributive Phenomenology}

Emotions are generally thought to be representational states which take as their objects evaluative properties - or, to put it in a less metaphysically committed way, emotions have evaluative content. Thus, fear is directed at the dangerous and sadness at loss. They are highly dependent upon what I shall call, for the sake of convenience if not elegance, 'Subjective Evaluative Conditions' (SEC): that compilation of a particular subject's (or perhaps some particular group of subjects) various motivations, interests, beliefs, goals, cares, values, character traits, imaginative and attentive capacities, other psychological characteristics, and even physical constitution, that forms the background conditions of a subject's emotional constitution and dispositions.

One could say, in other words, that the evaluative states of affairs which are the emotions' intentional objects supervene not just on objective, non-evaluative features of the world - the dog's sharp teeth; my grandmother's death - but also on a subject's particular SEC. So, my sadness at the death of my grandmother depends on my having cared for her, and my fear of the dog may depend on the (potentially false) belief, or even on a vivid imagining, that it is dangerous.

This feature of emotions poses a serious problem for the commonly upheld idea that emotions have objective truth conditions - that is to say, the idea that any episode of fear, for example, will be made true or false in virtue of the object or situation confronted being really dangerous, independent of the SEC on which the emotional reaction partly supervenes and hence to which its truth conditions are relative. I have argued at length for this elsewhere and there is no space to rehearse these arguments here. ${ }^{32}$ Nonetheless, I suggest that we should think of emotional truth and objectivity in terms of a kind of spectrum of apparent objectivity or appropriateness, running from most objective-seeming to least objective-seeming.

One of the key elements in this picture is what I call 'apparent voluntariness,' which refers to the degree of control to which emotions appear to be subject. The less control we do, or seem to have, over our emotional responses, or the more variation to which they are or appear to be subject, the more we are inclined to think of their truth conditions as less relative to SEC than otherwise, and the more the representational content of emotion will appear to approach that of perception. That is, the phenomenology of emotions will appear to us to be attributive in the way perception is, where we seem to see evaluative features of the world as objectively belonging to their objects.

The idea is this. For certain kinds of emotions and their eliciting conditions it may be that SEC play, and seem to us to play, a minimal determining role. The so-called basic emotions, when elicited by environmental factors that are closely one might say phylogenetically - connected to them, might admit of little or no variation in terms of response. For example, construing the death of loved ones as a loss to which sadness is the warranted response may be so hardwired and universal that any failure to feel sadness will necessarily be explained in a way consistent with

\footnotetext{
32 Cain Todd, "Emotional Objectivity, Attention, and the Phenomenology of Evaluative Content," in preparation.
} 
response-dependent accounts of evaluative properties, such as in terms of certain abnormal conditions. For such classes of pan-cultural, hardwired, environmentemotion relations, we may thus be able to think of them as involving something like response-dependent properties and hence as having something like straightforward objective truth conditions. The relevant response group will be relatively clear and easily identified.

There may be some contingent limits on relativity here, but these will just be contingent facts about the particular SEC constituting (some group of) human beings and does not suffice to undermine the point at issue, which is that the appearance of objectivity is subject to a scale dependent upon such contingent conditions.

At the other end of the spectrum we find the least objective-seeming emotional experiences, made up of more culturally variable, cognitively mediated, and sophisticated emotional responses, such as those typically included in the class of moral emotions but also, I contend, the class of aesthetic emotions, including those with which we are concerned. Here, the more we are aware of our own subjective contribution to the construal of the world the less perception-like (objective and attributive) our emotions will appear to us to be. As we shall see below, this is relevant to understanding the relative nature of bracketing and the degrees to which emotional engagement with fiction is subject.

Thus, the relativity to which emotional responses are subject comes in degrees, ranging from the (apparently) least changeable and most determinate - encompassing those responses that will appear to us to be most objective - to the (apparently) most variable and least constrained - including those responses which will appear to us to be less objective, less attributive, and more relative.

So how does all of this bear on the question at issue, understanding the nature of bracketing? It can, I suggest, give us a handle on the partially non-attributive phenomenology of emotion, but in order to see this it is necessary to look briefly at the equivalent phenomenology of attention.

Recently, in discussing some problems that attention poses for the representationalist theory of perception, Ned Block (2010) has provided the example of two Gabor patches, the one on the left having a $22 \%$ contrast, the one on right a $28 \%$ contrast and the $6 \%$ difference in contrast easily detectable by simply looking at both, with the focus of attention in the centre between each or evenly distributed over both patches. As he says, "When attention is to the left it increases the apparent contrast of the $22 \%$ patch (and decreases apparent contrast of the $28 \%$ patch) to the point of subjective equality between the two patches. With a bit of practice, one can voluntarily shift attention to the left or to the right and experience the increase from this diagram." 33 The point is that focal attention changes certain perceptual qualities, like perceived contrast, such that in the two cases (attention to the left, attention to the centre) there are two different phenomenal experiences of the same item with the same relevant instantiated property, i.e. $22 \%$ contrast, yet the experiences are different.

$\overline{33}$ Ned Block, “Attention and Mental Paint," Philosophical Issues 20 (2010): 36. 
In describing the role of attention in his example, Block convincingly claims that attentively seeing and less attentively seeing the same thing-the $22 \%$ patch-are experiences that differ phenomenally but not in the item seen or in its instantiated properties. Borrowing a phrase from Tyler Burge, he claims that attention lacks the phenomenology of objectivity: "The change invoked by changing attention does not look like a change in the world. There is something phenomenally different between the way the attended $22 \%$ patch looks and the way the unattended $28 \%$ patch looks, even if they are the same in perceived contrast." 34

The kind of prominence or salience added to perceptual experience by attention is - and appears to us, at least on minimal reflection, to be - a feature of experience rather than a property of the object perceived. Using a similar example but for different reasons, Sebastian Watzl has recently also argued that the prominence that is characteristic of an attended object is, unlike colour, not experienced as a property of that object, which it has independently of our attending to it. He characterises the nature of attention in the following way: "consciously attending to something does not just consist in being conscious of a certain way the world appears to be (it has a partially nonattributive phenomenology)." 35

One consequence that might be drawn from these observations is that attention has its own sui generis partially non-attributive phenomenology. One of the salient marks of this phenomenology is its being, like emotion, to some degree subject to the will, and hence its apparent voluntariness. Indeed, arguably this voluntariness is a natural concomitant of the partially non-attributive nature of attention's phenomenology since this latter is made apparent partly in virtue of the fact that we ourselves are involved in and can to some extent control the salience, prominence or determinateness that objects in the world 'take on' when they become the focus of attention. It is important again to stress that this voluntariness is, and can appear or not to us to be, a matter of degree. Sometimes we can deliberately focus on one feature at the expense of another; we can perhaps attend to two things simultaneously; we can switch and oscillate between objects of attention; we can also have our attention drawn, accidentally or deliberately, to features we had not noticed.

It is this notion, that attention involves voluntariness and has a partially nonattributive phenomenology that, I suggest, we can appeal to in order to understand and perhaps even explain the phenomenology and intentional content of emotion. Emotions can be thought of as having a partly non-attributive phenomenology, like attention. Indeed, it may be that there is more than mere resemblance here and that emotions borrow this aspect of their phenomenology from the role that attention plays in emotional/perceptual experience. It has, after all, been noted a by a number of thinkers that emotions serve to capture and consume attention and it may be in virtue of this that objects become salient, prominent and more

\footnotetext{
34 Ibid., p. 53.

35 Sebastien Watzl, "Attention as Structuring of the Stream of Consciousness”, in C. Mole, D. Smithies, W. Wu (eds.), Attention: Philosophical and Psychological Essays (Oxford: Oxford University Press, 2011), p. 153.
} 
determinate once emotional-attention is focussed on them. ${ }^{36} \mathrm{I}$ do not want to commit myself here, however, to any one picture of the exact relation between emotion and attention and will remain content with pointing out the similarities between them.

Having an emotional experience of fear towards the dog does not just consist in being conscious of a certain way the dog appears to be. More precisely, it is to construe it as threatening, and this construal, I contend, is partly non-attributive. Why? The dog's teeth remain sharp, its mouth snarling, its hairs bristling, and its manner threatening. Some of this is directly attributive and has a mind-to-world direction of fit, namely the purely perceptual non-evaluative features that figure in and to some extent constrain the experience. But note that already this characterization of the dog's manner is partly interpretive. It is crouching down, looking ready to pounce, snarling. But the threateningness that attaches itself to this perception, the dangerousness apparently inherent in the state of affairs, is clearly a construal that is dependent upon SEC, it is lent to the object in a way that is analogous to the way in which salience is lent to objects by attention.

It is the way in which these perceptible properties are emotionally coloured that constitutes the evaluative content of the experience. Insofar as this colouring is partly a result of and determined by SEC, we are doing some of the colouring of the world ourselves, even if some construals will appear to us to be more constrained by the non-evaluative features (and other factors) and hence more natural or more appropriate than others. Emotions, in other words, have a two-fold content, evaluative and perceptual, and the phenomenology of the former is, I contend, nonattributive while the latter is attributive. That is what makes the overall phenomenology partially non-attributive.

In short, how objective and attributive the phenomenology of emotion seems to $u s$ to be is a function in part of the apparent control we have over our responses, and of how aware we are of the our own role in colouring the world evaluatively. These features may not always be evident in our phenomenology and in these cases our emotions will appear to approach the mind-to-world, attributive, objective conditions of perception.

We are now, I think, in a position to understand more clearly how bracketing works and hence to understand the nature of our emotional engagement with fiction. The greater our awareness, phenomenologically, of the fictionality of $\mathrm{P}$ - the more prominent our epistemic relationship to $\mathrm{P}$ appears to us to be in our experience of attending to $\mathrm{P}$ - the less attributive the content of our emotional states will seem to be. This is so because, on the one hand, our attention to our own epistemic relationship to $\mathrm{P}$ involves the recognition that we ourselves are contributing, via our voluntary imaginative engagement, to the fictional evaluative content. So, this awareness of fictionality will colour the way in which the fictional content appears to us - namely, as something less than real. Indeed, although I do not have the space to argue for it here, I take the imagination itself to be wholly non-attributive, and this appears to us in our phenomenology of imagining. Similarly, on the other hand,

$\overline{36}$ See Michael Brady, "Virtue, Emotion, and Attention," Metaphilosophy 41 (2010): 115-131. 
the awareness of fictionality itself plays a role in limiting the attributiveness of the phenomenology of our emotions directed towards it.

As such, the more we are absorbed in the fiction and the less attentive we are to the fictionality of the content, the more attributive our emotions will seem to be, the more real the content will appear to be in our phenomenological awareness, and hence the more intense (ceteris paribus) our emotional reactions will be. This is just a consequence of the partially non-attributive nature of the phenomenology of emotion and attention. ${ }^{37}$

37 This paper was written with the generous support of the Swiss National Science Foundation. I would like to thank audiences in Geneva and Fribourg, Kevin Mulligan, and the two anonymous referees of this journal for their helpful comments. 